\title{
Modern methods of forming the motivational sphere of students in music classes
}

\author{
Irina Korsakova ${ }^{1, *}$, Vitalij Belobragin ${ }^{2,3,4}$, Ekaterina Putria $^{1}$, Nelli Islamova $^{1}$, Tatiana \\ Mozdykova $^{1}$, Svetlana Kuzichkina ${ }^{1}$ \\ ${ }^{1}$ Schnittke Moscow State Institute of Music, Moscow, Russia \\ ${ }^{2}$ Institute of Economics and culture, Russia \\ ${ }^{3}$ Russian Academy of natural Sciences, Russia \\ ${ }^{4}$ Academy of image science, Russia
}

\begin{abstract}
This paper discusses the concept of "motivation" in relation to the process of music education. The most effective ways of teaching are highlighted, which allow achieving a high level of motivation among students learning music, among which the method of active learning is recognized as the most effective for achieving this goal. The system of various motives that induce the student to educational activity is considered. Particular attention is paid to the process of formation and development of motives and needs; emphasis is placed on the importance of a personal approach to learning, taking into account the individual characteristics and abilities of each student. The personality of the teacher and the nature of his relationship with students are recognized as one of the fundamental factors affecting the success of training. The main pedagogical conditions that contribute to the increase of the motivational sphere of students are highlighted, such as: a personal approach, the creation of a special motivational atmosphere, the aspiration for the transition to self-education and self-development, the choice of the most effective forms of work. The conclusion is made about the necessary presence of internal motivation for the process of learning a subject (in this case, music) for productive educational activity. The problems in the field of music education are revealed, which consists in the lack of psychological knowledge among music teachers about the specifics of the formation of the motivational sphere of students.
\end{abstract}

\section{Introduction}

Motivation for learning is the most important component in the process of educating children. An activity leads to effective and high-quality results if a person, when performing it, has strong incentives that allow him to act with full dedication, actively, overcoming difficulties, without being distracted by secondary things. This also applies to any learning activity that will be more successful if the child has a positive attitude to the educational

\footnotetext{
* Corresponding author: korsakovaia@mail.ru
} 
process itself, has a cognitive interest, a sense of duty and responsibility, has a need to acquire new knowledge, skills and abilities.

The educational process is primarily aimed at the development of the personality of students, at the formation and expansion of the aspirations of children (motivating their activities). Nowadays, the issue of studying the motivational sphere of students is quite acute, because in pedagogical practice, the formation of motivation proceeds mainly spontaneously, uncontrollably and is more an achievement of the teachers themselves than the result of thoughtful, organized systematic work.

According to the results of the available research by Nikitskaya M.G. and Tolstykh N.N., it has been established that the educational activity of schoolchildren is stimulated by a whole system of various motives [1]. At each age and for each individual child, the same motives will have a different incentive force: some will be leading, main, others - secondary, additional, subordinate to the leading motives. So, in one case, the leading motives may be the desire to be an excellent student, to gain a leadership position in the class and the respect of peers, in the other - the desire to enter a certain university, to meet the requirements, and in the third case - an interest in knowledge itself. One of the most important tasks of the teacher is to establish the leading motive of the student in each individual case.

In the modern system of Russian education, the formation of the creative qualities of children occurs in the lessons of the aesthetic cycle, which also includes musical lessons. When teaching music, children develop an artistic-figurative, emotional-value perception of works of musical art. There is an to express their attitude to the world around them, to show their personal origin opportunity through creative independent activity. Art, music as an artistic way of cognizing life phenomena has one common object - a man, with all his general and individual traits and characteristics.

The theory and methodology of music education offer fairly general approaches to the professional impact on their students and their abilities. At the same time, each teacher feels that common approaches are often not enough, an individual "key" to the personality of each student, special psychological and pedagogical methods of influence are needed. Quite often, for more effective teaching of children, a teacher requires such skills as the ability to give up a leadership position in the creative process or in the process of generating ideas; to be led, not leading - to provoke their wards to show greater independence, and, as a result, teach them to take responsibility for themselves; have a high level of empathy, etc. In the work of the authors Marianna Alesi, Gaetano Rappo, Annamaria Pepi [2], such an approach that assumes active creative, emotional and intellectual participation of children is possible only under the careful guidance of a talented pedagogue while creating a special atmosphere for them - encouragement without evaluation, a psychological attitude (motivation) to achieve success, and not to prevent failure.

\section{Method}

Motivation and, as a consequence, aspiration in the study of T.O. Gordeeva [3] is the orientation of a person to perform such an activity that causes him positive emotions. The possibility of such an action turns into an incentive, and the satisfaction of the desire to act leads to an increase in the ability to effectively carry out this activity. Having information about the hobbies and interests of the child, it is possible to develop cognitive (intellect), emotional (empathy, involvement in pedagogical situations) and activity (obtaining the final result of activity) competencies in him. A well-organized psychological and pedagogical process of teaching music will allow the teacher to make the right choice among the teaching methods, which will maximize the motivation for achievement. Let us highlight and analyze in more detail several fundamental aspects that affect the improvement of the motivational sphere of students: 
I. Orientation to the personality of the student with his individual characteristics and abilities;

II. Creation of a supportive atmosphere, emphasis on striving for success, rather than on fear of failure;

III. Organization of independent activity, striving for self-development;

IV. Selection of effective forms of teaching.

I. Scientists Suzanne Hidi and K. Ann Renninger [4] believe that the emergence of individual interest in any subject is a consequence of the so-called "situational interest" supported by the teacher. As A. V. Toropova notes: "The psychological aspect of musical and pedagogical influence makes each teacher not only a teaching, instructing teacher... but also a diagnostician of the characteristics of the individuality of each child, a music psychologist who selects individual methods of his musical and psychological development, and an art therapist - in the event of the need for "help" or restoration of progressiveness in this development" [5].

According to the definition adopted in psychology, abilities are individual psychological characteristics that distinguish one person from another. Abilities are also defined by him as features related to the successful or unsuccessful performance of any activity. In the same activity, the development and improvement of abilities takes place. Consequently, the individual characteristics of the student should be the leading guideline for the teacher when building a strategy for the educational process.

Here, the teacher's diagnostics of the child's "primary zone of musicality" is very important, because the leading zone for each child may differ. Correct identification of the leading "primary" zone will help the teacher to competently influence each specific student and really increase the effectiveness of his musical activity, find the key to increasing motivation. Primary zones can be concentrated around several areas:

1) around the emotional-bodily response to music, the so-called musical reactivity. This area is defined as sensory sensitivity to music, and the student can be diagnosed as "musical sensing";

2) around active social sensitivity, when a student strives for collective musical activity, an active educational process, he has organizational abilities and a desire to take as much part as possible in social public projects (concerts, events, etc.). Such a student can be diagnosed as a "musical communicator";

3) according to the researchers A.I. Shcherbakova, Yu.V. Ganicheva. [6], around the spiritual and personal development of the student, when musicality is manifested in the desire for musical knowledge and immersion in the material even after school hours, in the search for images and meanings of the musical style and language being studied at the moment.

Knowing about the peculiarities of the leading "primary zones of musicality", the teacher can avoid a number of mistakes. So, the child's inactivity in the lesson, his closeness can be perceived by the teacher as a weak level of his musicality, lack of need (motivation) in musical activity, when in fact a given student may have poorly developed social need and educational communication (social sensitivity), which in no way affects his deep interest in music and emotional responsiveness. This example shows that behind an external feeling of lack of interest and motivation in a student, completely different problems can be hidden, requiring from the teacher the ability to find a personal approach to each student, the ability to diagnose the psychological and professional qualities and abilities of the child.

II. The living environment is the basis of all motivation. At the moment, in the psychological and pedagogical science, the problem of educational motivation has been studied quite widely. Often, the system of value of students (and, accordingly, the motivation of their activities) is formed by the youth environment (see for more details the article by Belobragin V.V., Groshev L.N. [7]). Parents play a significant role in creating a favorable atmosphere conducive to the personal and professional growth of the child. If the family is 
dominated by a tough authoritarian style of upbringing, where the emotions and needs of the child are suppressed, then his cognitive development is significantly reduced, external (bodily) and internal (emotional) constriction occurs, and resources are directed not to gaining knowledge, but to solving intra-family conflicts, search for ways to establish relationships with the closest people. This path of development of the child significantly affects his educational activity, can become the main cause of school failure, behavior problems, neurotic diseases.

If the leading emotion of the child in learning activity is fear (fear of failure, punishment, bad marks), then all his activities, all striving will be aimed at avoiding failure. The student will be extremely unsure of himself, any criticism will be perceived sharply negatively, educational activity will be associated with negative emotions and will not bring pleasure. The motive of avoiding failure will not lead to positive learning outcomes, this path is regressive. Such children mainly associate their failures with their lack of abilities, bad luck, they do not believe in the success of their activities, and if this happens, they justify it by the ease of the task or simple luck (depreciation occurs). Fear of failure often leads to reluctance to take on even the simplest tasks.

Students motivated to achieve success will behave differently. Usually, they see a certain positive goal in front of themselves and are actively involved in the process of achieving it, choosing suitable means for implementation. They competently assess their abilities and capabilities, taking into account the strengths and weaknesses. They perceive educational activity positively, emotions of interest and excitement prevail, internal resources are mobilized, and attention is concentrated on solving this problem. Failure, if so, will be perceived less painfully than in the children from the previous group, since it will be an experience necessary for further success. Obviously, in educational activities, as in life, it is necessary to develop the desire for success in children, to design situations that contribute to the successful performance of activities - "situations of success". Gordeeva T.O. and Sychev O.A. [8] have shown that "multi-interval" and "descriptive" assessments increase student learning motivation, while traditional assessments increase anxiety and do not contribute to their involvement in the educational process.

III. Teaching children to learn is one of the main tasks of a teacher and a sure way to increase motivation and improve the results of educational activities. Independent work is an essential part of the educational process. The famous music teacher H.G. Neuhaus believed that the teacher should become unnecessary to his student as soon as possible, i.e. instill in him such qualities as independent thinking, the search for the necessary methods of work, the desire for self-knowledge and the ability to achieve the set goal.

The connection between the development of creativity and the development of independence is obvious. Without independence, creativity can neither arise nor exist. Creative activity is a process of independent activity, free and individual. Therefore, the development of a creative personality must begin with the development of independence, with the formation of the desire and ability to express oneself, with the creation of conditions where the child's activity and initiative are respected and encouraged. Respecting the thoughts, feelings and ideas of his student, the teacher teaches his student to respect himself and other people. Self-respect refocuses the child's behavior towards self-education and selfstudy.

Fostering independence should begin with the first lesson. To teach a child to be creative in their studies, the teacher should always leave the student "food" for reflection and independent search. Coaching the student to meet certain requirements does not lead to either creative development or increased motivation. Musical works learned under the supervision and guidance of the teacher are forgotten almost immediately after passing the exam, since the teacher spent resources on learning a piece or etude in detail instead of teaching the child to work on them independently. After such an educational process, children remain helpless, 
incapable of independent activity. On the other hand, fulfilling someone's requirements and instructions rarely gives anyone pleasure and does not improve motivation. Getting used to the fact that all intellectual and search creative work is done by the teacher, the student becomes a passive participant in the educational process and does not strive for any independence. A similar study was carried out by foreign scientists Allan Wigfield, John T. Guthrie [9] in the field of primary education using the example of the reading lessons. It was found that students who completed the tasks of reading fiction and non-fiction literature had significant motivation to read and showed a high level of comprehension of the text.

A truly pedagogical approach is to teach a child to work independently. To do this, starting from the first lessons, the teacher needs to clearly imagine what knowledge, advice, methods, techniques and exercises the student will receive from him for further work without the teacher's help. Simply put, do not fight with him on a specific passage, but suggest all ways of working that will help to achieve an easy play of any passages; do not complain from lesson to lesson about mistakes in the text, but once and for all teach the correct approach to text analysis; do not reproach the student that he has not still learned by heart, but introduce him to methods that allow quickly memorizing musical works. Then your student will become very capable, he will begin to move forward!

The child should be able to "transfer" all theoretical knowledge and practical skills acquired in the lesson to homework. Clear goals and knowledge gained in the lesson are the basis for successful independent work. Western scientists Hulleman C.S., Harackiewicz J.M. [10] came to the conclusion that motivation for learning increases students' understanding of the applicability of knowledge and skills gained in the classroom in their later life. Motivation is the creation and support of students' interest in the material being studied. For learning to be interesting and effective, the child must understand what and why he is learning. A new thought, an idea should appear before him as a logical answer to the question that has arisen, as a way out of any problem situation.

IV. The choice of teaching methods for maximum motivation for achievement can become quite difficult for a music teacher, since each student has his own motivation and sometimes only a psychologist can determine it. But there are still some motivating aspects that are most common in children of primary education. Thus, the main source of educational motivation is the feeling of being an active participant in the educational process. The attitudes for active learning, formed at this age, will become the basis of the student's image in the future (see [11] for more details).

The method of active learning, as suggested in the work of Pieratt Jennifer Ray [12], assumes maximum involvement and active participation of students in the educational process. In this case, the teacher is not just a source of knowledge and skills that he must pass on to the student, and he, in turn, simply accept them. The teacher becomes a coordinator who helps his students in every possible way and encourages them to take action, organizer of an interesting and exciting atmosphere in the lesson, which contributes to the fact that the student himself begins to show activity and interest in the studied topic (occupation, subject). The method of active learning requires from the teacher much more energy consumption and a creative approach to presenting the material, but it gives much greater results than traditional forms of teaching.

In foreign studies by Heather Orpana, Caryn Pearson, Raelyne L. Dopko, Lucie Kocum [13] devoted to successful strategies in the field of learning, questionnaires are conducted using the VARK system, which allow identifying the preferences of the test taker and choosing the most successful learning strategy. The classification includes the following items:

- $\operatorname{visual}(\mathrm{V})$,

- $\operatorname{aural}(\mathrm{A})$,

- read/write (R), 
- kinesthetic (K).

Of course, in reality, people use a combination of several strategies when learning. Nevertheless, one of them usually prevails over the others, therefore, the Researchers emphasize that the technology of successful strategies helps choosing the most appropriate type of training, using not strengths, but personality preferences.

In pedagogy, there are several main forms of work that increase the level of activity and the inclusion of students in the educational process:

- using non-traditional forms of conducting lessons (lesson - business game, lesson competition, lesson - seminar, lesson - excursion, integrated lesson, etc.);

- using non-traditional forms of teaching (integrated classes united by a single topic, problem; combined, project classes, creative workshops, etc.);

- using game forms;

- dialogical interaction;

- problem-task approach (problematic issues, problem situations, etc., brainstorming);

- interactive teaching methods;

- using didactic tools (tests, terminological crosswords, etc.);

- introduction of developing didactic techniques;

- various types of homework;

- an activity-based approach to learning.

All of the above forms can be used in musical lessons in one way or another.

To increase and maintain educational motivation, it is worth influencing those psychological components, which mainly comprise the motivational sphere:

- awaken the emotion of interest (cognitive activity);

- develop self-confidence, the need for self-expression and self-respect;

- direct the child's attention to the achievement of success, and not to the fear of failure;

- actualize an independent creative position;

- nurture the need for social recognition;

- accept and approve the child's activities (by teachers and parents);

- provide regular opportunities for positive experiences, avoid anxiety and fear;

- explain the values of education;

- set clear and understandable goals that allow students to understand the essence of the educational process.

Obviously, in order to effectively increase the level of motivation in their classes, in some cases, a music teacher should move away from traditional forms of teaching and apply modern methods, techniques and forms of active learning, thus awakening in his students the desire for search, creativity, independent activity, increasing self-assessment of students and the effectiveness of their lessons.

\section{Results}

The results of the studies on motivation in the works of Marco Mula and Michael R Trimble [14] allow concluding that the educational activity of school-age children is stimulated not by one, but by a whole system of various stimulus and motives. For children of different ages and for each child individually, these motives may not have the same degree of motivation. As already noted, some motives can become leading, main, while others will catch up with the first group and play a secondary role.

All motives can be roughly divided into two large groups. The first group will be associated with the very process of educational activity, its content and conditions of implementation. This includes the cognitive interests of children, the desire for intellectual activity and activity, for acquiring new knowledge and skills. The second group of motives is associated with the child's relationship with the outside world (the so-called social group 
of motives). These motives are associated with a person's need to communicate with other people, with the assessment and influence of public opinion on the behavior of an individual, with the student's desire to take a certain, significant place for him in society. Research confirms that both of these categories of motives are important for successful learning (and for any productive activity in general).

The following ways of developing the needs of the student can be distinguished.

1. The process of a child's development through a change in his position in life, society and the system of interaction with people and the world around him directly affects the development of his motivational sphere. At each age, at different stages of his development, the child takes a different place in life, which determines the different requirements for him from others. It has been proven that a child can only experience emotional stability and wellbeing when he is able to really meet the requirements presented to him. This fact also gives rise to needs that correspond to each age stage. Thus, it was revealed that at the beginning of schooling, a child is guided by his new social position in society - the position of a schoolchild, which is very significant for the child. Then, the changes in his motivation are influenced by his position among peers, and after that, the position of the future member of society makes significant changes.

2. The process of a child's development, associated with the assimilation of new forms of behavior and activity, influences the formation of new needs. Many children who have learned to read have a need for reading, those who have learned to draw, cut, glue, etc. - in creative artistic activity, learned to listen to music - in interaction with musical art.

3. Each need develops within itself, going from elementary forms to more complex ones. A particularly striking example is the path of development of cognitive needs that proceeds in the process of educational activity of students: from an episodic unstable educational interest to complex forms of an incessant need for new knowledge.

4. Self-movement of needs. Studies show that when a desired need is satisfied, a child experiences not only calmness and contentment, but very bright and positive emotions. In an effort to prolong or enhance these sensations, the child begins either to improve the object of satisfying the need, or to look for new ways of satisfaction. This is how a qualitative change in the form of need occurs: a person is prompted to action not by need and necessity, but by the desire for a new experience - for achievement, possession. A person no longer just wants to be full, but begins to want to enjoy food, in connection with which he improves his diet, etc. Thus, the mental, spiritual needs of a person begin to become unsaturated, self-movement of need becomes possible.

The emergence of self-movement of highly spiritual needs, for example, in knowledge, art, creativity, is simply necessary for the full formation of the personality. With the development of these needs, the problem of internal stimulation of activity is solved, the permanent development of a person's personality occurs. The opposite has also been proven: the lack of growth of such needs leads first to stagnation, and later to the disintegration of the personality. Thus, according to Maratos A, Gold C, Wang X, Crawford M. [15], the development of a child's personality largely depends on what needs will acquire the form of self-movement in him. Music education, on the other hand, can help in solving this problem, making the craving for art, music, creativity and self-development the leading needs.

\section{Discussion}

The main tasks of children's music education are the development of the child's musicality and musical thinking. It is important to turn the educational process into an exciting action that will completely immerse the child in the world of music and creativity, encourage him to develop in the field of musical art. For this, it is extremely important to make the educational process for the child active (i.e. the child must be an active participant during 
learning), and turn the classes themselves into hobbies by increasing the student's personal interest in music lessons and by organizing the conditions under which the student will be able to show independence and creative initiative. Changing the attitude towards music lessons not as to compulsory and hard work, but as a child's own choice leading to joy and pleasure is the greatest stimulus and the best motivation for any work.

It is worth noting here that children with different levels of training and with different initial musical abilities enter the system of general music education. The main trend of music education in the 20th century was the availability of such education to absolutely all children. H. Neuhaus spoke about this in the following way: "I am convinced that a dialectically thought-out methodology and school should cover all degrees of giftedness - from the musically defective (because such a person also should learn music, music is an instrument of culture on an equal basis with others) to the spontaneously brilliant one", that "music schools should be the place where students get positive experiences and emotions associated with music, so that artistic music can be an actual part of their life" [16]. Nowadays, absolutely different children come to study music, and the teacher must find an approach and a "key" to each child.

The personality of the teacher in this situation is of paramount importance, and the relationship between teacher and student becomes the most important condition for the formation of motivation. The appearance of the teacher, his manner of communication, mood, love for children and the creation of a benevolent atmosphere - all have a special meaning in the course of the lesson. Creating a supportive atmosphere quite often helps to overcome negative attitudes towards teaching.

In the initial stages, it is very important to maintain positive emotions in the child, and the situation of success creates such positive experiences. It is important to remember that too easy work leading to success does not bring the necessary satisfaction to the child. A difficult, but feasible and surmountable task makes the educational process exciting, although it causes tension, it leads to greater satisfaction. Not fear of a bad grade or failure, but an incentive to curiosity and overcome encountered difficulties creates a higher level of motivation, helps solving a more complex creative problem, and shows the importance of new knowledge and skills for further work. As noted in the work of Michael Trimble and Dale Hesdorffer [17], it is the joint work of the teacher and the student that mainly manifests both the level of the teacher's skill and the success of a student.

Let us note a few key points that help improving motivation, which a teacher-musician should rely on when conducting a lesson:

- contact between a teacher and a student in the process of artistic-creative and musical cognitive activities will be the most complete and effective with the most enthusiastic, deep immersion in the study of musical material;

- a teacher who is overprotective of his student may miss the moment when it is necessary to change the nature of teaching, giving the child more freedom of action, and provide a greater credit of trust;

- a commensurate balance between the student's abilities and the requirements for his activity is needed. For the emergence of intrinsic motivation, requirements should not exceed abilities, and abilities - requirements;

- the emergence of intrinsic motivation is facilitated by providing students with freedom of choice and maintaining a balance between students' autonomy and control over their actions.

\section{Conclusions}

The presence of intrinsic motivation for the process of learning a subject is necessary for the most productive learning activity. There are two main types of motivation - striving for success and avoiding failure. Students with motivation of achievement, focused on success 
and able to overcome difficulties in achieving the set goal, are much more effective than students, whose motives are motivated by fear of failure or poor grades.

When forming motivation in the learning process, it is important to maximally activate the student's cognitive activity, which is facilitated by the creation of a "situation of success" in the classroom. This situation is a combination of some conditions that will ensure the student's success in completing the assignment, and the success itself will be the result of this situation. It is important to remember that the constant provision of the success of learning can also lead to the opposite results - to the formation of not an active, but a habitual and sometimes passive attitude towards learning.

Lessons with a student, especially musical ones, are a creative process. The teacher must realistically assess his strengths and weaknesses, as well as the capabilities and abilities of his student. Competently organized psychological and pedagogical process of teaching music will allow the teacher to make the right choice among teaching methods, which allows achieving maximum motivation for achievements, in relation to each individual student. To do this, he needs to take into account several factors:

- focus on the personality of the student with his individual characteristics and abilities;

- strive to create a favorable atmosphere in the classroom;

- encourage independent activity of the student, teach him exactly the process of "learning" and self-organization, and transfer to the mode of independent learning over time;

- choose effective forms of teaching, the leading of which is the principle of active learning.

To form a high level of motivation of his students, the teacher needs to understand and realize the ways of developing the motives and needs of each of them, for which a deeper and more detailed psychological and pedagogical study of this problem is required. This is the relevance of this study. In most cases, modern children have insufficient emotional development, which makes it difficult to express themselves through musical art. To eliminate these psychological clamps, it is necessary to develop such psychological and pedagogical methods and means that will maximize the disclosure and emotional release in creative activity.

In music lessons, it is necessary to take into account the individual characteristics of the student, to apply proven and innovative psychological and pedagogical methods aimed at developing motivation for creative activity, which will contribute to the formation and development of not only musical abilities, but also the general intellectual abilities of the student. The sphere of motivation requires from teacher-musicians a deeper and more detailed study and understanding from the standpoint of psychology. Only a conscious, goaloriented and consistent approach in the study and application of methods and techniques of motivation will lead to the most effective educational process and the desired results.

\section{References}

1. M.G. Nikitskaya, N.N. Tolstykh, Electronic journal "Modern foreign psychology" 7(2), 100-113 (2018) DOI: https://doi.org/10.17759/jmfp.2018070210

2. M. Alesi, G. Rappo, A. Pepi, Journal Article https://doi.org/10.1177\%2F2158244015589995

3. T.O. Gordeeva, UOJ 62 (2016) DOI: 10.17223/17267080/62/4

4. S. Hidi, K. Ann Renninger, Educational Psychologist 41(2), 111-127 (2006) https://doi.org/10.1207/s15326985ep4102_4

5. A. Toropova, T. Lvova, The European Proceedings of Social \& Behavioural Sciences (EpSBS) conference proceedings XLIII, 482-488

DOI: 10.15405/epsbs.2018.07.63 
6. Y.V. Ganicheva, A.A. Davidova, A.V. Smirnov, N.S. Yushchenko, A.I. Shcherbakova, E-SdPTCONICIT - Espacios (ISSN07981015-Venezuela-Scopus) 38(40), 12 (2017)

7. V.V. Belobragin, L.N. Grosheva, Scientific notes of the Russian State Social University 15.2 (135), 30-36 (2016) DOI: 10.17922/2071-5323-2016-15-2-30-36

8. T.O. Gordeeva, O.A. Sychev, Vestnik of Moscow University. Series 14. Psychology 1, 67-87 (2017) DOI: 10.11621/vsp.2017.01.69

9. A. Wigfield, J.T. Guthrie, Handbook of Research on Schools, Schooling and Human Development https://doi.org/10.4324/9780203874844.ch29

10. C.S. Hulleman, J.M. Harackiewicz, Science 326(5958), 1410-1412 (2009) doi:10.1126/science. 1177067

11. V.V. Belobragin, Higher education today 8, 74-78 (2019) DOI: 10.25586/RNU.HET.19.08.P.74

12. J. Ray Pieratt, CGU Theses \& Dissertations (2011) https://doi.org/10.5642/cguetd/13

13. H. Orpana, C. Pearson, R.L. Dopko, L. Kocum, Health Promotion and Chronic Disease Prevention in Canada 39(1), 25-32 (2019) https://doi.org/10.24095/hpcdp.39.1.03

14. M. Mula, M.R. Trimble, Clinical Medicine 9(1) (2009) DOI: https://doi.org/10.7861/clinmedicine.9-1-83

15. A. Maratos, C. Gold, X. Wang, M. Crawford, Cochrane Database of Systematic Reviews 1, CD004517 (2008) https://doi.org/10.1002/14651858.CD004517.pub2

16. M. Chmurzynska, Procedia - Social and Behavioral Sciences 45, 306-317 (2012) https://doi.org/10.1016/j.sbspro.2012.06.567

17. M. Trimble, D. Hesdorffer, BJPSYCH International 14, 2 (2017) DOI: https://doi.org/10.1192/S2056474000001720 